Asian-Australasian Journal of

Food Safety and Security

ISSN 2523-1073 (Print) 2523-2983(Online)

www.ebupress.com/journal/aajfss

\title{
Article \\ Consequences of use of fenpropathrin compared to other fish toxicants in commercial aquaculture
}

\author{
Md. Mokhlesur Rahman ${ }^{1 *}$, Md. Shahjahan Ali Sarker ${ }^{2}$, M. Nazrul Islam ${ }^{3}$ and Nazmul Hoque ${ }^{2}$ \\ ${ }^{1}$ Institute of Environmental Science, University of Rajshahi, Bangladesh \\ ${ }^{2}$ Department of Microbiology and Hygiene, Bangladesh Agricultural University, Mymensingh, Bangladesh \\ ${ }^{3}$ Department of Zoology, University of Rajshahi, Bangladesh
}

*Corresponding author: Md. Mokhlesur Rahman, Institute of Environmental Science, University of Rajshahi, Bangladesh. E-mail: mailtomokhles@yahoo.com

Received: 16 April 2019/Accepted: 18 May 2019/ Published: 30 May 2019

\begin{abstract}
Use of fish toxicants is an important management tool in inland commercial aquaculture. In entrepreneurial fishery in northwest Bangladesh where pond ownership (using rights due to lease) changes frequently (every few years) use of fish toxicants is very routine and more crucial. Along with some traditional fish toxicants (rotenone and aluminium phosphide), unconventional and insecticides like fenpropathrin (not approved for aquaculture use) are being used by fish farm owners in northwest Bangladesh. The study was conducted to understand the consequences of use of fenpropathrin compared to other traditional fish toxicants in commercial aquaculture for harvesting of food fish. Of all the toxicants, fenpropathrin' s impact was lowest on zooplankton and aquatic insect population, while rotenone had the lowest impact on benthos population in terms of killing and quick recovery time for the population, primarily due to the high turbidity (suspended soil particle) of the pond water (under this study) by which both fenpropathrin and rotenone got affected. Aluminium phosphide found to be more damaging in terms of killing and relatively longer recovery time for zooplankton, aquatic insect and benthos population. Using convenience, quick killing, cheaper price, short duration of toxicity and no potential long-term damage of the waterbody contributes positively for fenpropathrin as fish toxicant except the severe potential public health concern from eating of fish killed by fenpropathrin due to very high bioconcentration factor of fenpropathrin; hence, demands regulation of fenpropathrin' $\mathrm{s}$ use as fish toxicants for food fish.
\end{abstract}

Keywords: fenpropathrin; fish toxicant; aquaculture; zooplankton

\section{Introduction}

Commercial pond aquaculture has its unrelenting pressure of economic necessity to produce fish in most efficiently but inexpensively as possible (Lennon et al., 1970). Use fish toxicants as a management tool allows the commercial fish farmers of northwest Bangladesh to have greater control over the fish stock management (elimination of undesired species, complete harvesting of all fish of the waterbody, elimination and restart of fish culture etc.). Rotenone, a natural toxicant derived from leguminous plants mainly found in southeast Asia, Latin America and east Africa (Finlayson et al., 2000) is highly toxic to fish and aquatic life but significantly less toxic to birds and mammals made it favorable as piscicide, hence used historically as most environmentally benign pesticide (Ling, 2003). Most of the fish species exhibit higher sensitivity to rotenone than most of the aquatic invertebrates (Durkin, 2008). Based on the comprehensive ecological and human health risk assessment US EPA (2007) declared that rotenone is eligible only for piscicidal use. Apart from rotenone's using difficulty, to ensure killing of fish species that are relatively hardy (catfish, Channa sp., Tilapia sp., Anabus sp etc.) may require use of unusually high amount of rotenone, which increases the cost significantly. 
As an alternative to rotenone, like other parts of the country most of the commercial fish farmers in northwest Bangladesh use aluminium phosphide tablets (phostoxin) as fish toxicant; a chemical normally used as fumigation agent against grains-storage pests (Braid, 1994; Chowdhury et al., 2012; Rasul et al., 2017). According to Perschbacher and Sarkar (1989) phostoxin (aluminium phosphide) incurred lowest concentration $(0.25 \mathrm{ppm})$ and lowest cost to attain $100 \%$ kill in 24 hours of relatively hardy species, Channa punctatus of many fish toxicants (sumithion, bleaching powder, dieldrin, phyphanon, rotenone, phostoxin and DDVP) used in aquaculture ponds at $27^{\circ} \mathrm{C}$ temperature. Rahman et al. (1992) noted that in earthen aquaculture pond aluminium phosphide toxicity lasts 10 to 15 days as opposed to 10 to 12 days for rotenone in Bangladesh. Farmers involved in commercial fishery in northwest Bangladesh are continuously looking for alternative of phostoxin (aluminium phosphide), due to the operational difficulties like broadcasting of phostoxin pills in the pond, which is hazardous to the broadcaster as well and then waiting for couple of hours at least after the application in the middle of the night to get the fish killed before netting, in addition to the long detoxification period.

In these circumstances, synthetic pyrethroid, fenpropathrin came into play. Fenpropathrin, is a broad spectrum pyrethroid insecticide and acaricide, first synthesized in 1971 by Suitomo chemical company ltd and commercialized in late 1980's (Kanawi et al., 2013). In Bangladesh fenpropathrin is registered for controlling of red mites in eggplant and tea (DAE, 2019). Valent USA incorporation (marketer of Danitol in Florida USA) categorized fenpropathrin as 'restricted use pesticide' due to its toxicity to fish and aquatic organisms (Valent, 2009). Due to its convenience of use, extreme toxicity to fish and relatively lower price that makes the use of high-enough concentration economically viable to obtain quick kill (within an hour) of fish; commercial fish farmers in northwest Bangladesh have started using fenpropathrin (Danitol) as fish toxicant to kill food fish. The study was conducted to compare the ecological consequences of fenpropathrin' $s$ use as fish toxicant compared to the traditional fish toxicants in commercial fish farming in northwest Bangladesh.

\section{Materials and Methods}

For this study 3 different farmers were identified in Parila union of Poba upazilla of Rajshahi district who intended to use different fish toxicants namely fenpropathrin (Danitol), rotenone and aluminium phosphide (phostoxin) in commercial aquaculture ponds. Accordingly, the author was present with the farmers at the time of treatment. Different farmers used the treatment in different times in between March and May of 2019.

\subsection{Fenpropathrin application}

The total amount of ('Danitol' 10 EC imported marketed by Setu corporation ltd) fenpropathrin were poured into a big aluminium pot and diluted with water. Then the dilution was broadcasted along the water edges of the whole pond, and as far as it can be thrown (approximately 5 meters) towards the middle of the pond. The treatment took place on 4 April 2019, 4.00 am in aquaculture pond with water area of two acres.

\subsection{Rotenone application}

Farmer took half of the rotenone powder ('Aquanone powder' containing 9\% rotenone, marketed by agrovet division of square pharmaceuticals ltd.) in a big aluminium pot, little bit of water was added to make dough of rotenone powder in such condition that balls can be made using the dough. Then the balls of rotenone powder were thrown into the water mostly in the middle part of the waterbody. The rest half of the rotenone was diluted in a big aluminium pot with water, then the dilution was broadcasted along the water edges of the pond and as far as it can be thrown (approximately 5 meters) towards the middle. To avoid the rotenone powder from getting into his respiratory system, farmer covered his nose and mouth with a towel at the time of dilution. The treatment took place on 12 May 2019, 1.30 am in aquaculture pond with water area of one acre.

\subsection{Phostoxin application}

Farmer used a towel to cover his nose and mouth before he opened the can of phostoxin tablets ('Mimtox' containing 57\% aluminium phosphide, imported and marketed by Mimpex agrochemicals ltd.) to avoid the phostoxin fumes from getting into his respiratory system. Then the tablets were thrown into the pond. Because of the large size of the tablet's farmer was able to through those homogeneously throughout the pond including the middle part of the pond. The treatment took place on 24 May 2019, 1.30 am in aquaculture pond with water area of four and half acres.

From each treatment, samples of zooplankton, water insects and benthos were collected at day before (previous day) and after 1 day, 2 days, 5 days and 10 days of the treatment. From each of the treatment, each day sampling was done 3 times and was considered as 3 replications. After each of the treatment, chemical concentration was 
back calculated based on the size of the water body, water depth and quantity of the fish toxicants (percentage of active ingredient) used. Water samples ( 3 replications) from one-foot depth of each water body was taken before the treatment and after completion of (3 times) netting in post treatment stage. Then turbidity for each sample was measured using turbidity meter in the lab.

\subsection{Zooplankton sampling}

A cone shape plankton net (specification- 200 US with 75 to 85 microns mesh size) was used for zooplankton sampling. The wide end of the net was fitted with a round metal frame and the tapering end was fitted with a collection bottle. Holding the meatal frame, the net was towed for certain distance in the pond water, one foot below the surface. Then the collected samples from the collection bottle were taken into a plastic bottle, added with 5\% formalin as preservative. The process was performed three times for each sampling and were considered as three replications. The collected samples represented the total amount of water passed through the plankton net, calculated by using following formula: Water volume in liter = 'л (3.14)' multiplied with 'square radius of the plankton net metal frame in meter' multiplied with 'distance the net was traversed through in meter' multiplied with 1000. The zooplankton sample was transferred to the lab. Using a compound microscope and Sedge-wick Rafter cell counter (Welch 1948), zooplankton type and density was counted and expressed in numbers/liter of pond water.

\subsection{Sampling of aquatic insects}

A square shape fine meshed net bag fitted with a bamboo frame (1 meter by 1 meter) at the open end was used for collecting aquatic insect sample. The net was towed in the water along the edge of the pond for 3-meter distance. The collected insects were transferred in a plastic jar with 5\% formalin solution. The process was performed three times for each sampling and was considered as three replications. Then the samples were taken to the lab where the insects were identified and counted.

\subsection{Sampling of benthos}

For collection of benthos sample, a metal scoop (2.76 inches diameter and 1.5 inches depth) was used to collect the mud from the pond bottom at 18 inches depth from the surface. A total of three scoops of mud was collected from 3 different locations of the pond to constitute three replications. The mud samples were then transferred into separate plastic bags and carried to the lab. The mud samples were then washed under running water on a fine meshed sieve. The benthos separated from the mud, then was transferred into a Petri dish from the sieve. Some tap water was added into the petri dish and the benthos was observed and counted under bright light.

\section{Results and Discussion}

Based on the calculation, rotenone, aluminium phosphide and fenpropathrin were found to be used at 0.272 $\mathrm{mg} / \mathrm{liter}, 0.61 \mathrm{mg} / \mathrm{liter}$ and $0.065 \mathrm{mg} /$ liter respectively. Water temperature was around $30^{\circ} \mathrm{C}$ for all ponds during the time of fish toxicants use.

Rotenone concentration of $0.272 \mathrm{ppm}$ was good enough to kill and harvest all the carp species in this study but not good enough to kill the predatory species like Channa punctatus. Rotenone concentration of $2.5 \mathrm{ppm}$ is required to achieve 100\% kill of C. punctatus within 24 hours (Perschbacher and Sarkar, 1989). Within one week after the harvest the ownership of the pond (where rotenone study was conducted) got changed, and new owner used phostoxin (aluminium phosphide @ $0.86 \mathrm{ppm}$ ) to ensure killing of all weed fish. As a result, many C. punctatus was observed dead and floating on the water, that successfully survived the rotenone treatment. 96-hour LC $_{50}$ value of Oncorhynchus mykiss is recorded as $0.0097 \mathrm{mg} /$ liter for aluminium phosphide by IUPAC (2018), but Perschbacher and Sarkar (1989) required a concentration of $0.25 \mathrm{ppm}$ of aluminium phosphide to obtain $100 \%$ kill of $C$. punctatus within 24 hours. The doses exercised $(0.61 \mathrm{mg} / \mathrm{liter})$ in this experiment were higher than the doses mentioned above and was effective to kill all the fish (Indian and Chinese carps). 


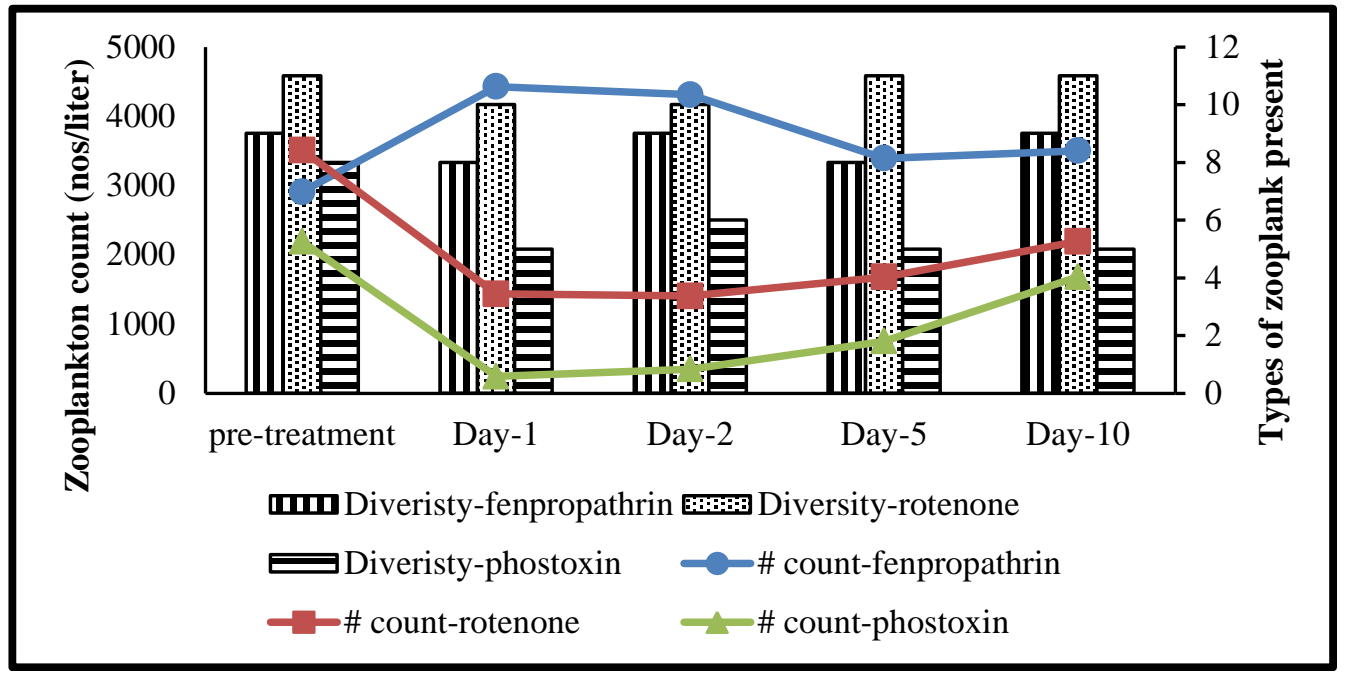

Figure 1. Total count (nos/liter) of zooplankton and diversity before and after use of different fish toxicants in commercial aquaculture ponds.

Zooplankton total count (nos/liter water) increased 52\% at 24 hours point (was not anticipated!) after use of fenpropathrin@0.065mg/liter, while the zooplankton total count (nos/liter water) declined by 59\% and 89\% respectively at 24 hours point after use of rotenone @ $0.272 \mathrm{mg} / \mathrm{liter}$ and aluminium phosphide @ $0.61 \mathrm{mg} / \mathrm{liter}$ (Figure 1). From day 2 to 10 days point after fenpropathrin treatment zooplankton count gradually declined, but for rotenone and aluminium phosphide treatment zooplankton count gradually kept increasing. Like the zooplankton count, zooplankton diversity (types of zooplankton available) was affected in phostoxin treatment where diversity count reduced to five after 10 days of the treatment from initial count of eight. Given that during the experimental period no fish feed was supplied, and there was no fish released, there was neither additional nutrient supply nor predation from fish, let the zooplankton population grow and survive (after the initial blow of fish toxicant use), which was mostly determined by the existing nutrient supply and physico-chemical factors of the pond.

48-hours LC $_{50}$ value of Dhaphnia magna for fenpropathrin is $0.53 \mathrm{ppb}$ (PMEP, 1989) whereas for aluminium phosphide 48-hour $\mathrm{EC}_{50}$ value of $D$. magna is $0.37 \mathrm{ppm}$ (IUPAC, 2018). Given fenpropathrin's extreme toxicity to aquatic organisms (Valent, 2009; Chemwatch, 2012), the influx of zooplankton count in fenpropathrin experiment was quite surprising. The explanation for this unusual zooplankton response lays in the water turbidity data of the treatment pond.

Table 1. Water turbidity of treatment ponds before and after treatment (and netting in between) with various fish toxicant.

\begin{tabular}{lllll}
\hline $\begin{array}{l}\text { Sl. } \\
\text { No. }\end{array}$ & Treatment ponds & $\begin{array}{l}\text { Pretreatment } \\
\text { turbidity (ntu) }\end{array}$ & $\begin{array}{l}\text { Post treatment (after } 3 \text { times } \\
\text { netting) turbidity (ntu) }\end{array}$ \\
\hline 1 & Rotenone treatment pond & 21.31 & 62.18 \\
2 & Aluminium phosphide (phostoxin)- pond & 27.74 & 65.44 \\
3 & Fenpropathrin (Danitol) treatment pond & 34.57 & 83.56 \\
\hline
\end{tabular}

In the pretreatment stage the water turbidity of fenpropathrin treatment (due to prior netting) pond (Table 1) was higher than the other treatment ponds especially than rotenone pond. Several times of netting immediately after the use of the fish toxicants to harvest fish increased the pond water turbidity in between two to three-fold of the pretreatment stage. Due to fenpropathrin' s strong absorbance by soil, it is very resistant to leaching and there is no risk of ground water contamination in normal circumstances (ARNICA and AWHHE, 2014). Fenpropathrin' s nonpolar nature resulted in very low water solubility causes it to be sorbed strongly to organic matter and soil to avoid contact with water (Kanawi et al., 2013); highest turbidity of pre and post treatment (after netting) pond water have resulted in binding of fenpropathrin with the soil particle at a greater degree and more quickly, has surely made it unavailable in the pond water in short term and result in relatively quick detoxification of water (tested by releasing few fish on test basis after 4 days of treatment) compared to aluminium phosphide treatment. Day (1991) also observed 20 to $80 \%$ reduction in pyrethroid induced mortality of Daphnia magna 
due to the presence of humic material. Due to the application method (farmer broadcast fenpropathrin along the water edges) of fenpropathrin large middle portion of the waterbody didn't received any fenpropathrin.

24-hour LC $_{50}$ value of Daphnia pulex and Diaptomus siciloides for rotenone was $<0.025$ ppm (Hamilton, 1941). Despite the use of higher doses of rotenone (@0.272 ppm) and aluminium phosphide $(0.61 \mathrm{ppm})$ zooplankton population declined but not got wiped out. Due to the large size of the pond ( 1 acre for rotenone treatment, and 4.5 acres for aluminium phosphide treatment, 2 acres for fenpropathrin treatment) and sheer volume of water the mixing of all the fish toxicants (rotenone, aluminium phosphide and fenpropathrin) in pond water was surely not homogeneous. Despite of several times of netting for catching fish, the inconsistency in mixing left blank space in the water body where some of the zooplanktons (due to their slow-moving nature) never encountered the fish toxicants. Whereas fast moving fish encountered the toxicants and was killed.

Presence of heat, light and oxygen makes rotenone unstable; rotenone also gets absorbed by sediment and suspended soil particle in water (Ling, 2003). Gilderhus et al. (1988) found rotenone loss to be 10 times faster at temperatures above $23^{0} \mathrm{C}$ than $1^{0} \mathrm{C}$ in shallow ponds, and half-life was generally less than 1 day in natural water at temperatures above $20^{\circ} \mathrm{C}$. Absorption of rotenone by the suspended soil particle in water and faster decay of rotenone, helped recover the zooplankton population in the experiment relatively faster than that of aluminium phosphide treatment.

Table 2. Zooplankton count (nos/liter) before and after use of fenpropathrin, phostoxin and rotenone in commercial aquaculture pond.

\begin{tabular}{|c|c|c|c|c|c|c|}
\hline Toxicant & Zooplankton & Pretreatment & Day-1 & Day-2 & Day-5 & Day-10 \\
\hline \multirow{11}{*}{$\begin{array}{l}\text { Fenpropathrin } \\
@ 0.065 \mathrm{mg} / \mathrm{liter}\end{array}$} & Brachionus sp. & $892 \pm 34$ & $1654 \pm 122$ & $1512 \pm 301$ & $1135 \pm 217$ & $1201 \pm 225$ \\
\hline & Keratella sp. & $822 \pm 138$ & $1236 \pm 19$ & $913 \pm 219$ & $748 \pm 80$ & $622 \pm 110$ \\
\hline & Cyclops sp. & $148 \pm 64$ & $97 \pm 45$ & $15 \pm 25$ & $7 \pm 13$ & $71 \pm 21$ \\
\hline & Nauplius & $375 \pm 100$ & $435 \pm 55$ & $346 \pm 50$ & $333 \pm 95$ & $383 \pm 39$ \\
\hline & Polyarthra sp. & - & $88 \pm 92$ & $361 \pm 116$ & $315 \pm 86$ & $264 \pm 74$ \\
\hline & Diaptomus sp. & $7 \pm 12$ & - & - & - & - \\
\hline & Asplanchna sp. & $356 \pm 55$ & $523 \pm 206$ & $660 \pm 168$ & $484 \pm 150$ & $535 \pm 158$ \\
\hline & Daphnia sp. & $75 \pm 48$ & $16 \pm 28$ & $15 \pm 27$ & - & $24 \pm 25$ \\
\hline & Moina sp. & $13 \pm 23$ & - & - & - & - \\
\hline & Filinia sp. & - & - & $278 \pm 126$ & $173 \pm 47$ & $299 \pm 265$ \\
\hline & Trichocerca sp. & $219 \pm 149$ & $377 \pm 118$ & $208 \pm 132$ & $196 \pm 86$ & $101 \pm 54$ \\
\hline \multirow{9}{*}{$\begin{array}{l}\text { Aluminium } \\
\text { phosphide } \\
\text { mg/liter }\end{array}$} & Brachionus sp. & $651 \pm 72$ & $54 \pm 13$ & $35 \pm 25$ & $40 \pm 37$ & $111 \pm 88$ \\
\hline & Cyclops sp. & $634 \pm 102$ & $61 \pm 21$ & $86 \pm 22$ & $174 \pm 121$ & $625 \pm 94$ \\
\hline & Nauplius & $566 \pm 77$ & $102 \pm 40$ & $193 \pm 86$ & $380 \pm 242$ & $586 \pm 29$ \\
\hline & Polyarthra sp. & - & - & - & $24 \pm 42$ & - \\
\hline & Diaptomus sp. & $109 \pm 44$ & $20 \pm 20$ & $14 \pm 25$ & - & $208 \pm 119$ \\
\hline & Asplanchna sp. & $159 \pm 29$ & $7 \pm 12$ & $7 \pm 12$ & $134 \pm 93$ & $152 \pm 49$ \\
\hline & Daphnia sp. & $36 \pm 32$ & - & $14 \pm 12$ & - & - \\
\hline & Moina sp. & $21 \pm 21$ & - & - & - & - \\
\hline & Diaphanosoma sp. & $14 \pm 13$ & - & - & - & - \\
\hline \multirow{11}{*}{$\begin{array}{l}\text { Rotenone } \\
0.272 \mathrm{mg} / \text { liter }\end{array}$} & Brachionus sp. & $584 \pm 91$ & $337 \pm 270$ & $414 \pm 138$ & $481 \pm 59$ & $566 \pm 110$ \\
\hline & Keratella sp. & $151 \pm 262$ & $20 \pm 35$ & - & $45 \pm 23$ & $63 \pm 28$ \\
\hline & Cyclops sp. & $428 \pm 78$ & $87 \pm 65$ & $105 \pm 76$ & $255 \pm 38$ & $346 \pm 107$ \\
\hline & Nauplius & $1191 \pm 280$ & $715 \pm 680$ & $704 \pm 283$ & $549 \pm 37$ & $520 \pm 87$ \\
\hline & Polyarthra sp. & $138 \pm 240$ & $88 \pm 152$ & - & $15 \pm 13$ & $19 \pm 19$ \\
\hline & Diaptomus sp. & $270 \pm 77$ & $67 \pm 100$ & $13 \pm 23$ & $92 \pm 24$ & $156 \pm 57$ \\
\hline & Asplanchna sp. & $269 \pm 119$ & $74 \pm 94$ & $83 \pm 63$ & $155 \pm 39$ & $178 \pm 91$ \\
\hline & Daphnia sp. & $15 \pm 26$ & $7 \pm 12$ & $13 \pm 12$ & $22 \pm 22$ & $97 \pm 59$ \\
\hline & Moina sp. & $343 \pm 141$ & - & $7 \pm 12$ & $29 \pm 34$ & $155 \pm 85$ \\
\hline & Diaphanosoma sp. & $89 \pm 154$ & $13 \pm 23$ & $21 \pm 36$ & $22 \pm 22$ & $81 \pm 21$ \\
\hline & Filinia sp. & $31 \pm 54$ & $27 \pm 46$ & $27 \pm 32$ & $15 \pm 25$ & $13 \pm 11$ \\
\hline
\end{tabular}

Zooplankton composition in fenpropathrin experiment (Table 2) shows that the influx of Brachionus sp., Keratella sp. and Asplanchna sp. were the main reason of increasing the total zooplankton count after one day of fenpropathrin use. Zooplankton diversity (genus count) remain same after fenpropathrin's use, though the genus composition was different. Of all zooplankton types Moina sp. and Diaptomus sp. (less abundant at 
pretreatment level) were most affected, disappeared after the use of fenpropathrin and didn't show up till the end of the observation (10 day) period. On the other hand, Polyarthra sp. and Filinia sp. were not found at pretreatment sampling but showed up after 1 day and 2 days respectively of the use of fenpropathrin. It is most likely that they were present even in pretreatment stage but due to their lower number didn't show up at sampling.

Zooplankton composition in aluminium phosphide experiment (Table 2) showed that Moina sp. and Diphanosoma sp. were affected most; disappeared after the treatment and didn't showed up till the end of the observation period of 10 days after the treatment. Brachionus sp., Cyclops sp., nauplius, Diaptomus sp. and Asplanchna sp. declined sharply $(92,90,82,82$ and $96 \%$ respectively) in number after one day of aluminium phosphide treatment. Abundance of Cyclops sp., nauplius, Diaptomus sp. and Asplanchna sp. recovered to the pretreatment level by the end of the observation period but Brachionus sp. count remained low.

Zooplankton composition (Table 2) in rotenone treatment showed that Moina sp. disappeared completely after 1 day of the treatment but showed up again after 2 days of the treatment. Brachionus sp., Keratella sp., Cyclops sp., nauplius, Polyarthra sp., Diaptomus sp., Asplanchna sp., Daphnia sp. and Diaphanosoma sp. declined 42, $87,80,40,37,75,72,55$ and $85 \%$ respectively after one day of rotenone's use. Zooplankton population showed continuous recovery within the observation period of 10 days.

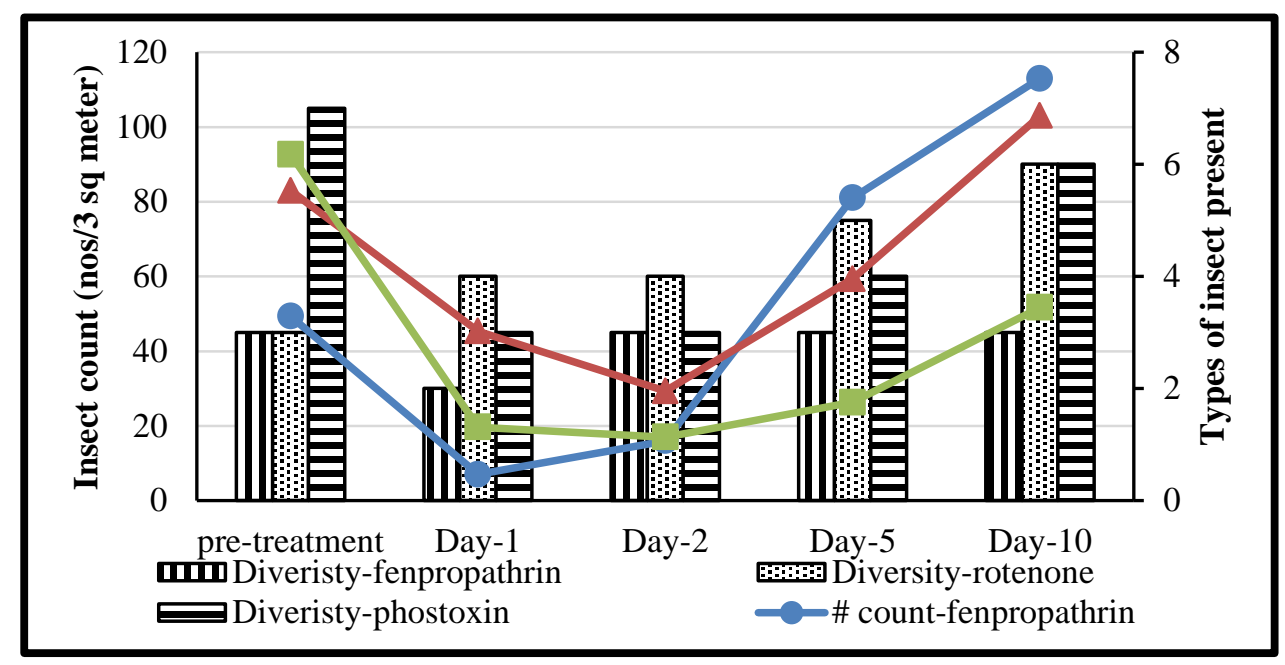

Figure 2. Total count (nos/3 sq meter) and diversity of aquatic insects before and after use of different fish toxicants in commercial aquaculture pond.

Total insect count in fenpropathrin and aluminium phosphide treatment was found to be lowest after one day of the treatment, declined 86 and $82 \%$ respectively from the pretreatment level (Figure 2). Lowest total insect count (a decline of $64 \%$ of pretreatment level) for rotenone treatment found to be on day-2 after the treatment. Insect number reached back to the pretreatment level within 5 days of fenpropathrin treatment, compared to within 10 days in case of rotenone treatment. The recovery in insect count is slowest in case of aluminium phosphide treatment and fastest in fenpropathrin treatment. In fact, insect count didn't reach to the pretreatment level for aluminium phosphide within the observation period of 10 days. In addition to inconsistency of mixing, quick decay of rotenone due to high environmental temp (around $35^{\circ} \mathrm{C}$ ) and strong absorption of fenpropathrin by the suspended soil and humic particle of the pond water reduced the endurance of toxicity of rotenone and fenpropathrin quicker than the toxicity of aluminium phosphide. Insect diversity (genus count) also got down from seven at pretreatment level to three after one day of aluminium phosphide treatment. From day- 5 of the aluminium phosphide treatment the diversity started to increase, and the diversity count reached to six on day 10 at the end of the observation period. Insect diversity increased after the rotenone treatment from three at pretreatment level to six on day 10 after the treatment. Crawling beetles and tadpoles showed up towards the end of the observation period of rotenone treatment, which were not available at pretreatment stage. 
Table 3. Aquatic insect count (nos/3 sq meter) before and after use of fenpropathrin, phostoxin and rotenone in commercial aquaculture pond.

\begin{tabular}{|c|c|c|c|c|c|c|}
\hline Toxicant & Aquatic insects & Pretreatment & Day-1 & Day-2 & Day-5 & Day-10 \\
\hline \multirow{5}{*}{$\begin{array}{l}\text { Fenpropathrin } \\
@ 0.065 \mathrm{mg} / \mathrm{liter}\end{array}$} & Boatman & $46.3 \pm 22$ & $6.7 \pm 8.3$ & $5.3 \pm 3.2$ & $68.7 \pm 52.4$ & $98 \pm 114$ \\
\hline & Backswimmer & $2.7 \pm 0.6$ & - & $0.7 \pm 1.2$ & $1.0 \pm 1,7$ & $6.3 \pm 4$ \\
\hline & Gerris sp. & $0.3 \pm 0.6$ & - & - & - & - \\
\hline & Nepa sp. & - & $0.3 \pm 0.6$ & - & - & - \\
\hline & Crawling beetle & - & - & $10 \pm 2.6$ & $7.4 \pm 8.7$ & $8.7 \pm 4.7$ \\
\hline \multirow{7}{*}{$\begin{array}{l}\text { Aluminium } \\
\text { phosphide } \\
\text { mg/liter }\end{array}$} & Boatman & $59.3 \pm 17.2$ & $15 \pm 10.1$ & $11.0 \pm 6$ & $12.3 \pm 6.1$ & $21 \pm 9.2$ \\
\hline & Backswimmer & $27.3 \pm 19$ & - & - & - & $5 \pm 3.6$ \\
\hline & Gerris sp. & $0.7 \pm 0.6$ & - & - & - & $0.7 \pm 0.6$ \\
\hline & Water scavenger & $0.3 \pm 0.6$ & $1.0 \pm 1.0$ & $1.3 \pm 1.5$ & $4.7 \pm 2.1$ & $4.0 \pm 2.6$ \\
\hline & Crawling beetle & $3.0 \pm 3.0$ & $3.7 \pm 2.1$ & $4.7 \pm 1.2$ & $6.7 \pm 2.1$ & $12 \pm 5.6$ \\
\hline & Dragon fly & $1.7 \pm 1.2$ & - & - & - & - \\
\hline & Damselfly & $0.3 \pm 0.6$ & - & - & $2.7 \pm 1.5$ & $9.0 \pm 5.0$ \\
\hline \multirow{6}{*}{$\begin{array}{l}\text { Rotenone } \\
0.272 \mathrm{mg} / \text { liter }\end{array}$} & Boatman & $5.7 \pm 3.1$ & $8.0 \pm 6.6$ & $9.7 \pm 4.0$ & $36 \pm 9.6$ & $59.0 \pm 18.5$ \\
\hline & Backswimmer & $76.7 \pm 79.2$ & $36.7 \pm 8.4$ & $19.0 \pm 10.4$ & $17.3 \pm 8.5$ & $32.3 \pm 8.0$ \\
\hline & Gerris & $0.7 \pm 0.6$ & $0.3 \pm 0.6$ & $0.3 \pm 0.6$ & $0.7 \pm 0.6$ & $0.3 \pm 0.6$ \\
\hline & Water scavenger & - & $0.3 \pm 0.6$ & $0.3 \pm 0.6$ & $0.3 \pm 0.6$ & $0.3 \pm 0.6$ \\
\hline & Crawling beetle & - & - & - & $5.0 \pm 2.0$ & $8.0 \pm 2.6$ \\
\hline & Tadpole & - & - & - & - & $2.7 \pm 0.6$ \\
\hline
\end{tabular}

Insect composition in fenpropathrin experiment (Table 3) showed that boatman declined 88\%, backswimmer and Gerris sp. were absent after one day of fenpropathrin treatment. From day two of the fenpropathrin treatment, both boatman and backswimmer count started to increase. Insect count at the end of the observation period was dominated by boatman, though backswimmer number got some bump as well. Of the insects Gerris sp. got disappeared after the fenpropathrin treatment and never showed up. Gerris sp. is fast moving a surface dweller and fenpropathrin was broadcasted on the water, made the fast-moving surface dweller Gerris sp. became victim of toxicity fenpropathrin before it got absorbed by the suspended soil and humic particle. Nepa $\mathrm{sp}$. was another insect that was only found at Day-1 of the treatment in semi-dead condition, but it never showed up again afterwards. The timing of half-dead Nepa' s catch in fenpropathrin treatment indicated the bottom dwelling Nepa sp. got affected from the sediments which absorbed fenpropathrin from being suspended in the water column during the experiment that got settled on the bottom. Insect diversity at the pretreatment (Table 3) and at the end of the observation period remain same due to the appearance of crawling beetles from day-2 of the observation period. Given, this beetle can fly it is not impossible for it to arrive from side by side ponds, because during first two sampling (pretreatment and day 1) it was not found.

Of the insects in aluminium phosphide treatment, dragon fly nymph (which has long reproductive cycle) was most affected, got disappeared due to the treatment and did not appear again within the observation period (Table 3). Backswimmers also got disappeared after the treatment but showed up again on $10^{\text {th }}$ day after the aluminium phosphide treatment. Boatman number got drastically down $(81 \%$ decline at day 2 from the pretreatment level) but slowly recovered like Gerris sp. and damselfly larvae in the aluminium phosphide treatment. Water scavenger and crawling beetle were almost not affected in aluminium phosphide treatment and in fact their number slowly but steadily got increased till the end of observation period.

In rotenone treatment (Table 3) backswimmer number gradually declined (77\% of the pretreatment level) after the treatment till 5 days then increased but not reached the pretreatment level within the observation period (10 days after treatment). 24-hour $\mathrm{LC}_{50}$ value of backswimmer for rotenone was recorded as $0.1 \mathrm{mg} / \mathrm{liter}$ by Hamilton (1941). Opposite to the backswimmer, number of boatmen kept increasing after the treatment and reached the highest count at the end of observation period of 10 days. Gerris sp. was not affected, the number remain low but steady all along the observation period. 


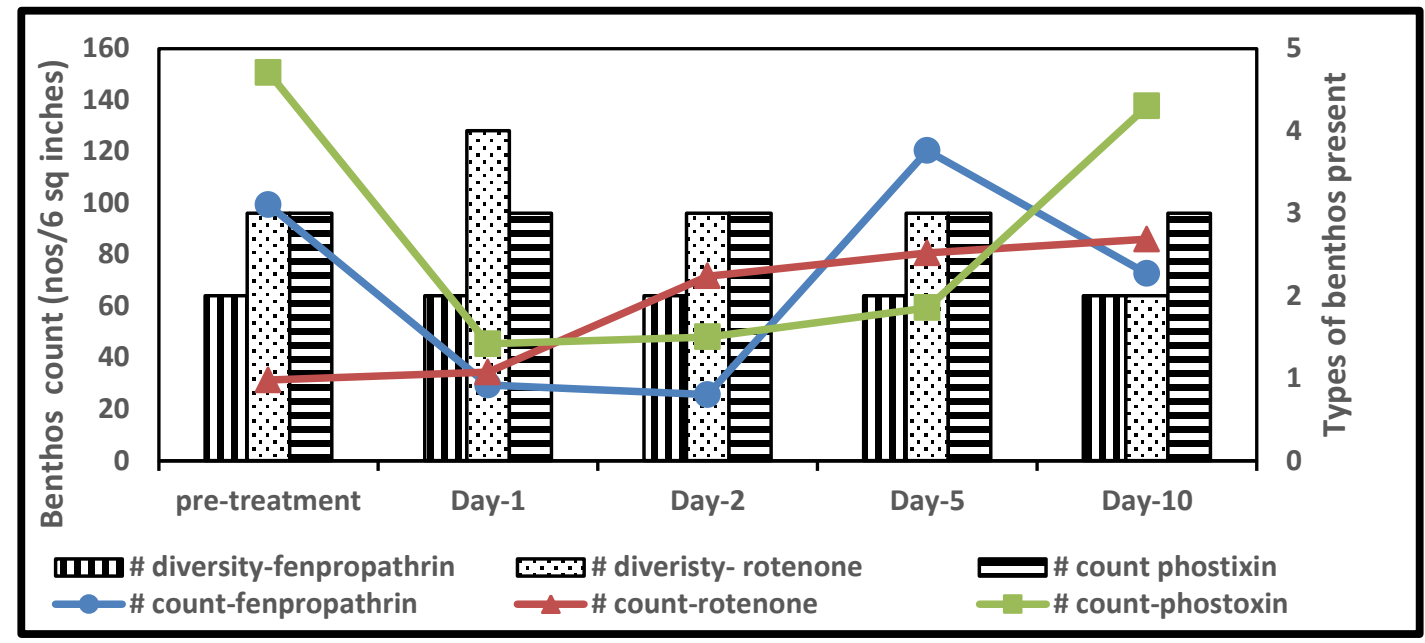

Figure 3. Total count (nos/6 sq inches) of benthos before and after use of different fish toxicants in commercial aquaculture ponds.

Unlike the rotenone treatment (Figure 3) one day after use of fenpropathrin and aluminium phosphide the benthos count declined (74 and $70 \%$ respectively) sharply, signifies the toxicity of those two toxicants to benthos population. Benthos population count exceeded the pretreatment level within 5 days of fenpropathrin treatment but didn't sustain the number and declined a bit at day-10 after the treatment. The recovery of benthos population took longest in aluminium phosphide treatment. On the other hand, benthos population in rotenone treatment continuously kept increasing till the end of the observation period indicates no negative impact of rotenone on benthos population. Diversity count for benthos in case of all three treatments found to be not affected.

Table 4. Benthos count (nos/6 sq inch bottom) before and after use of fenpropathrin, phostoxin and rotenone in commercial aquaculture pond.

\begin{tabular}{|c|c|c|c|c|c|c|}
\hline Toxicant & Benthos & $\begin{array}{l}\text { Pre } \\
\text { treatment }\end{array}$ & Day-1 & Day-2 & Day-5 & Day-10 \\
\hline \multirow{2}{*}{$\begin{array}{l}\text { Fenpropathrin } \\
@ 0.065 \mathrm{mg} / \mathrm{liter}\end{array}$} & Chironomid larvae & $34.3 \pm 3.5$ & $3.3 \pm 0.6$ & $0.7 \pm 0.6$ & $41 \pm 6.6$ & $16.7 \pm 4.5$ \\
\hline & Tubifex & $65.0 \pm 8.5$ & $26 \pm 17$ & $25 \pm 10.6$ & $79.3 \pm 3.5$ & $56 \pm 11.5$ \\
\hline \multirow{2}{*}{$\begin{array}{l}\text { Aluminium } \\
\text { phosphide } \\
\text { mg/liter }\end{array}$} & Chironomid larvae & $70.7 \pm 7.4$ & $3.3 \pm 1.5$ & $2.7 \pm 0.6$ & $4.3 \pm 4.5$ & $124.0 \pm 100$ \\
\hline & $\begin{array}{l}\text { Tubifex } \\
\text { Leech } \\
\text { Polychaeta }\end{array}$ & $\begin{array}{l}78.7 \pm 8 \\
1.3 \pm 0.6 \\
-\end{array}$ & $\begin{array}{l}41.3 \pm 11.7 \\
- \\
0.7 \pm 0.6\end{array}$ & $\begin{array}{l}44.7 \pm 17.2 \\
- \\
0.7 \pm 1.2\end{array}$ & $\begin{array}{l}54 \pm 9.8 \\
- \\
1.0 \pm 1.0\end{array}$ & $\begin{array}{l}12.7 \pm 4 \\
- \\
1.0 \pm 1.0\end{array}$ \\
\hline \multirow{2}{*}{$\begin{array}{l}\text { Rotenone } \\
0.272 \mathrm{mg} / \text { liter }\end{array}$} & Chironomid larvae & $13.3 \pm 1.5$ & $18.3 \pm 8.1$ & $13.3 \pm 9$ & $17.7 \pm 3.5$ & $22.7 \pm 4.2$ \\
\hline & $\begin{array}{l}\text { Tubifex } \\
\text { Leech } \\
\text { Polychaeta }\end{array}$ & $\begin{array}{l}14.3 \pm 1.5 \\
3.7 \pm 1.2 \\
-\end{array}$ & $\begin{array}{l}15.0 \pm 4.0 \\
0.3 \pm 0.6 \\
0.7 \pm 1.2 \\
\end{array}$ & $\begin{array}{l}57.3 \pm 10.6 \\
- \\
1.0 \pm 0\end{array}$ & $\begin{array}{l}62.7 \pm 8.5 \\
- \\
0.3 \pm 0.6\end{array}$ & $\begin{array}{l}63.3 \pm 12.5 \\
- \\
- \\
\end{array}$ \\
\hline
\end{tabular}

In fenpropathrin treatment (Table 4) both the chironomid larvae and tubifex number found to be in synchrony with each other at different samplings. An influx of both chironomid larvae and tubifex (mostly young and small) were observed at day five after the treatment from their lowest count at day-two of fenpropathrin treatment. Population count for all those young individuals (for both chironomid and tubifex) didn't sustain due to the left-over toxicity of the pond sediments that absorbed the fenpropathrin and hence many of them died resulted in lower population count for both chironomid larvae and tubifex (regular size) at day-10 of fenpropathrin treatment. The response of benthos population in fenpropathrin treatment are in alignment with ARNICA and AWHHE (2014) characterization of fenpropathrin as moderately toxic to earthworms. Also, tiny snails showed up from the day-5 after the treatment (not shown in Table 4) and their number increased on day 10 of the observation period, while in the pretreatment stage they were not found. In commercial aquaculture 
ponds in northwest Bangladesh farmers always rear some black carp along with other cultured carp species, for biological control of snails, but the absence of snail eater fish (back carp) may have led the production of snails. Leech was most affected in aluminium phosphide treatment, disappeared after the treatment and didn't come back again within the observation period. Chironomid population in aluminium phosphide treatment found (Table 4) to be lowest (96\% decline of the pretreatment level) on day-2 after the treatment but swung back after day-5 of the treatment and exceeded the pretreatment level at day-10 of the observation period. On the other hand, tubifex population declined to a lesser extent ( $47 \%$ decline on day one) than chironomid larvae; seemed stabilized in the middle but declined again towards the end to score the lowest count at day-10 after aluminium phosphide treatment, opposite to the influx of chironomid larvae at that point of time (Table 4). Polychaetae number found to be very stable at post treatment stage till the end of the observation period, though it was absent in pretreatment level (most probably to the sampling error). Like the fenpropathrin treatment (not shown in the Table 4) lot of tiny snails were observed at the day-10 after aluminium phosphide treatment. Absence of snail eater black carp has allowed snails to reproduce.

Benthos population composition in rotenone treatment showed (Table 4) that none other than leech was impacted by the use of rotenone. 48-hour $\mathrm{LC}_{50}$ value of leech for rotenone was recorded as $<0.1 \mathrm{mg} / \mathrm{l}$ by Hamilton (1941). Leech was found at pretreatment sampling and after one day of rotenone's use. But from the day-two to 10 days after the treatment leech was not found. Tubifex population count found to be increased drastically on day-2 after the treatment and the high number continued to be there till the end of the observation period. Count for chironomid larvae slowly increased in rotenone treatment over the pretreatment level towards the end of the observation period.

\subsection{Health impact}

Fish killed using fish toxicant in commercial fishery by the farmers in northwest Bangladesh are sold in the market as food fish. Therefore, there is always a concern about the food safety of the fish killed by using fish toxicant. For fenpropathrin maximum residue level (MRL) value is not set for fish/meat by the European Commission of EU. But fenpropathrin MRL for all food items except citrus fruits are set to be $0.01 \mathrm{mg} / \mathrm{kg}$ (EC, 2019). Acceptable daily intake (ADI) level was set by joint FAO/WHO meeting on pesticide residues (JMPR) as 0 to $0.03 \mathrm{mg} / \mathrm{kg}$ body weight, and acute reference dose (ARfD) was also set as $0.03 \mathrm{mg} / \mathrm{kg}$ (Shah and McGregor, 2012). Al-Makkawy and Madbouly (1999) found bioconcentration factor of fenpropathrin for Tilapia nilotica heads and flesh to be respectively 130 and 7 respectively at 3 days of the treatment @1 $\mu \mathrm{g}$ fenpropathrin/liter water. Given the high bioconcentration factor 225 for fenpropathrin in fish (Giddings and Campasino, 2007) indicates that based on the doses of fenpropathrin (@65 $\mu \mathrm{g} /$ liter) used in this study would leave $14.625 \mathrm{mg}$ fenpropathrin per kilogram of fish theoretically, which is way higher than the MRL value $(0.01$ $\mathrm{mg} / \mathrm{kg}$ ) for fenpropathrin. Given the concentration of fenpropathrin in this study, if a child weighted $20 \mathrm{~kg}$ consumes $100 \mathrm{~g}$ of such fish then the intake of fenpropathrin will be $0.07 \mathrm{mg} / \mathrm{kg}$ exceeding the ARfD value set by JMPR. But given the high toxicity of fenpropathrin to fish if lower doses (than the doses used in this experiment) are used as fish toxicant, could be still effective in killing fish especially in winter since fenpropathrin is more toxic in cold water than warm water (Kanawi et al., 2013) and may leave fish with lower concentration of fenpropathrin.

MRL for rotenone is set as $0.01 \mathrm{mg} / \mathrm{kg}$ for almost all food items by the European Commission of EU (EC 2019). BPDB (Bio-Pesticide Database) (2019) recorded bioconcentration factor for rotenone as 26 than the ambient condition where ADI value was not available. Relatively lower bioconcentration factor of rotenone compared to fenpropathrin for fish and no set ADI value by the regulators indicates rotenone's relative safety as fish toxicants even for food fish. On the other hand, bioconcentration factor for aluminium phosphide has been reported as low risk by IUPAC (2018). Though there is set ADI $0.019 \mathrm{mg} / \mathrm{kg}$ and ARfD $0.032 \mathrm{mg} / \mathrm{kg}$ (IUPAC, 2018), but given to low bioconcentration factor in fish, use of aluminium phosphide as fish toxicant for food fish and consumption of those may not have any health consequences. Rahman et al. (1992) also described fish killed with the use of rotenone and aluminium phosphide are suitable for human consumption.

\subsection{Economics}

Perschbacher and Sarkar (1989) found aluminium phosphide to be most inexpensive (given the required concentration of $0.25 \mathrm{ppm}$ ) among following fish toxicants: rotenone, sumithion, phyphanon, aluminium phosphide, DDVP and bleaching powder, where cost of organophosphorus pesticides (fenpropathrin was not included in the study) were deemed to be prohibitive for the commercial fish farmers to be used as fish toxicants. Combination of fenpropathrin' $\mathrm{s}$ toxicity to fish and low cost (similar or bit lower than even aluminium phosphide per unit area of water body) has made that economic barrier (that had prevented other 
pyrethroid' s use as fish toxicant) obsolete in current situation. Moreover, it has allowed farmers to obtain quick kill (within an hour after use) hence convenient, regardless of ecological consequences and serious health concern.

\section{Conclusions}

Significant factors such as ease of application, short duration of toxicity, no risk of future inhibition of production potential of the pond and low price, that dictates farmers choice of fish toxicants (Lennon et al., 1970) are all in favor of fenpropathrin's use in killing of food fish in northwest Bangladesh but rings the alarm for fish consumer due to severe health concern; hence it demands to be strongly regulated to be used as fish toxicants for food fish.

\section{Conflict of interest}

None to declare.

\section{References}

Al-Makkawy H and M Madbouly ,1999. Persistence and accumulation of some organic insecticides in Nile water and fish. Resources, Conservation and Recycling, 27: 105-115.

ARNICA and AWHHE, 2014. Fenpropathrin. Available at: http://awhhe.am/wpcontent/uploads/2014/02/chemicals_eng/fenpropathrin.pdf

Baird DJ, 1994. Pest control in tropical aquaculture: An ecological hazard assessment of natural and synthetic control agents, Internationale Vereinigung für Theoretische und Angewandte Limnologie: Mitteilungen, 24: 285-292.

Bio-pesticide data base (BPDB), University of Hertfordshire. 2019. Rotenone. Available at: https://sitem.herts.ac.uk/aeru/bpdb/Reports/587.htm

Chemwatch, 2012. Fenpropathrin. Available at: http://datasheets.scbt.com/sc-257526.pdf

Chowdhury AKJ, D Saha, MB Hossain, M Shamsuddin and MH Minar, 2012. Chemicals used in freshwater aquaculture with special emphasis to fish health management of Noakhali, Bangladesh. African Journal of Basic \& Applied Sciences, 4: 110-114.

DAE (Department of Agricultural Extension), 2019. List of registered agricultural pesticides, bio pesticides and public health pesticides in Bangladesh. Available https://dae.portal.gov.bd/sites/default/files/files/dae.portal.gov.bd/page/8a812db0_3544_4105_b066_df7807 4d3efb/Registered\%20Agricultural\%20PesticidesList\%20(4).pdf

Day KE ,1991. Effects of dissolved organic carbon on accumulation and acute toxicity of fenvalerate, deltamethrin and cyhalothrin to Daphnia magna (Straus). Environmental Toxicology and Chemistry, 10: 91101.

Durkin PR, 2008. Rotenone human health and ecological risk assessment: Final report. Syracuse Environmental Research Associates, Inc., Fayetteville, New York. 217 P. Available at: https://www.fs.fed.us/foresthealth/pesticide/pdfs/0521103a_Rotenone.pdf

European Commission (EC), 2019. EU pesticide database. Available at: http://ec.europa.eu/food/plant/pesticides/eu-pesticidesdatabase/public/?event=pesticide.residue.CurrentMRL\&language $=\mathrm{EN}$

Finlayson B, R Schnick, R Cailteux, L DeMong, W Horton, W McClay, C Thompson and G Tichacek, 2000. Rotenone use in fisheries management: administrative and technical guidelines manual. American Fisheries Society, Bethesda, Maryland.

Giddings J and K Campasino, 2007. Bioconcentration, biotransformation and biomagnification of pyrethroids. Compliance Services International. $253^{\text {rd }}$ ACS national meeting, San Francisco, CA. Available at: http://www.complianceservices.com/wp-content/uploads/2017/05/Bioconcentration-biotransformation-andbiomagnification-of-pyrethroids.pdf

Gilderhus PA, VK Dawson and JL Allen, 1988. Deposition and persistence of rotenone in shallow ponds during cold and warm seasons. U.S. Fish and Wildlife Service Investigations in FishControl 95.

Hamilton HL, 1941. The biological action on freshwater animals. Proceedings of the Iowa Academy of Science, 48: 467-479.

IUPAC (International Union of Pure and Applied Chemistry), 2018. Aluminium phosphide. Available at: https://sitem.herts.ac.uk/aeru/iupac/Reports/523.htm 
Kanawi E, R Budd and RS Tjeerdema, 2013. Environmental fate and ecotoxicology of fenpropathrin. In DM Whitacre (ed.), Reviews of environmental contamination and toxicology. Vol-225. Springer Science + Business Media. New York. 151p.

Lennon RE, JB Hunn, RA Schnick and RM Burress, 1970. Reclamation of ponds, lakes, and streams with fish toxicants: a review. FAO Fish. tech. Pap., (100):99 p. Available at: http://www.fao.org/3/B0465E00.HTM\#toc

Ling N, 2003. Rotenone-a review of its toxicity and use for fisheries management. Department of Conservation, Wellington, New Zealand. 40P.

Rahman MM, I Varga and SN Chowdhury, 1992. Manual on polyculture and integrated fish farming in Bangladesh. GOB, UNDP and FAO. /87/045/91/11. Available at: http://www.fao.org/tempref/FI/CDrom/aquaculture/a0845t/volume2/docrep/field/003/ac375e/AC375E03.htm \#ch2.3.1

Rasul MG, BC Majumdar and $\mathrm{T}$ Akter, 2017. Aqua-chemicals and Antibiotics Used in Freshwater Aquaculture of Sylhet, Bangladesh. Journal of Agricultural Science and Engineering, 3: 20-26.

Perschbacher PW and J Sarkar, 1989.Toxicity of selected pesticides to the snakehead, Channa punctata. Asian Fishery Sci., 2: 249-254.

Pesticide management education program (PMEP), Cornell University. 1989. Fenpropathrin - Chemical Fact Sheet 12/89. Available at: http://pmep.cce.cornell.edu/profiles/insect-mite/fenitrothionmethylpara/fenpropathrin/fenprop_cfs_1289.html

Shah PV and D McGregor, 2012. Fenpropathrin. Joint FAW/WHO meeting on Pesticide Residue (JMPR), 253305 p. Available at: http://apps.who.int/pesticide-residues-jmpr-database/Document/55

USEPA, 2007. Reregistration Eligibility Decision for Rotenone (EPA 738-R-07-005)

Valent, 2009. $\quad$ DANITOL ${ }^{\circledR} \quad 2.4 \quad$ EC $\quad$ Spray. Available at: https://www.valent.com/Data/Labels/FL090003\%20Danitol\%20-\%20Asian\%20Citrus\%20Psyllid.pdf

Welch PS, 1948. Limnological Methods, McGraw Hill Book Company, New York. 381pp. 